\title{
Una aproximación a la noción de exemplum en la obra luliana, seguida de un breve comentario en los exempla del capítulo 62 del Llibre de meravelles ${ }^{1}$
}

\author{
RUBÉN LUZÓN DíAZ \\ Universitat de València
}

\section{El propósito misionero de Llull como base de su escritura}

La singularidad del beato mallorquín Ramon Llull en el ámbito de la literatura medieval se explica fundamentalmente a partir de su interés recurrente, desde el momento de su conversión hacia 1263 , por poner toda su capacidad de acción al servicio de lo que él llamaba la "primera intenció", consistente en conocer, amar y alabar a Dios, mediante la aplicación adecuada de la «segona intenció», relativa a los menesteres propios de este mundo (los cuales han de quedar siempre subordinados, por tanto, a la consecución de la intención primera). Después de la crisis que le llevó a convertirse a la causa cristiana, Llull no dejó de reafirmarse en su convicción de que toda la creación (y subrayamos el concepto de creación para dar cuenta de la lejanía de Llull respecto de cualquier concepción emanatista del mundo) ha sido efectuada por Dios en un acto de suprema bondad, grandeza, poder, sabiduría y otras virtudes y que, en todo cuanto existe, es posible rastrear las semejanzas que las criaturas dan de su creador. Por esta razón, de acuerdo con el orden natural reconocible en todas las cosas por disposición divina (la cual es necesariamente justa, ya que una de las principales virtudes de la divinidad es precisamente la justicia), Llull insistirá permanentemente en que el ser humano está llamado a cantar siempre las grandezas del Creador y a esforzarse no sólo por amarlo, sino aun por conocerlo intelectivamente y darlo a conocer a los no creyentes por medio de «razones necesarias».

Tras su conversión, Llull formuló el triple propósito en que, al menos durante sus primeros años de activismo religioso, cifraría la mayor parte de sus esfuerzos. En primer lugar, se proponía predicar a los infieles hasta llegar al martirio. En segundo lugar, pretendía escribir «el millor llibre del món» contra el error de esos mismos infieles. Finalmente, buscaría la fundación de escuelas o monasterios destinados a la formación e instrucción de misioneros que no tuviesen miedo a ofrecer la vida por la fe; esa formación debía garantizar el

1 Este trabajo se inscribe en el proyecto de investigación HUM2005-06110-C02-01/FILO, financiado por el Ministerio de Educación y Ciencia, y se ha beneficiado de una beca predoctoral FPU, también del Ministerio de Educación y Ciencia [referencia AP2005-0137]. 
aprendizaje del árabe y otras lenguas orientales que sirviesen a los misioneros como herramientas útiles de persuasión «en tierras extrañas». El mismo Llull, antes de lanzarse frenéticamente a escribir y a viajar por medio mundo, advirtiendo que apenas tenía conocimientos de gramática latina (dato que haremos bien en relativizar), inició en 1265 un largo período de formación autodidacta que se alargaría hasta 1274, durante el cual aprendió la lengua arábiga, según leemos en la Vida coetània (cf. la traducción catalana de Anthony Bonner en $O S$ I: $11-50$ ).

Nos interesa centrar la atención en el interés de Llull por escribir «el millor llibre del món». ¿A qué se refería exactamente el beato mallorquín cuando, en realidad, contamos con no menos de doscientos escritos suyos, dejando de lado todos los apócrifos, igualmente numerosos?

El Llibre de contemplació en Déu, obra monumental escrita entre 12711274 , es la primera creación escrita original de Llull (si pasamos por alto la $L \grave{o}$ gica d'Algazel, especie de ejercicio «escolar» basado en la obra del filósofo árabe al-Gazzali) y constituye, sin duda, su primer intento de elaborar un detallado compendio de la estructura de la creación y de la necesidad de que el ser humano se ponga al servicio de los designios divinos. Sin embargo, a pesar de su extraordinaria longitud, el Llibre de contemplació no constituirá más que un ensayo inicial donde ya se pueden identificar, sin duda, materiales decisivos en el desarrollo de obras posteriores, aunque todavía en estado embrionario, como ha observado lúcidamente Josep Enric Rubio (1997). Cuando Llull redacte poco después, su Art abreujada d'atrobar veritat (obra de la cual nos ha quedado tan sólo el texto latino), nos hallaremos ante la primera versión del Ars luliana, que no es sino la matriz ideológica y de pensamiento que constituirá el fundamento lógico de toda su obra posterior. En cuanto tal, el Ars admitirá, a lo largo de la producción escrita de Llull, sucesivas reelaboraciones. La más compleja de todas, la Art demostrativa, fue compuesta, en opinión de Bonner, en 1283; las versiones posteriores irán viéndose progresivamente simplificadas, hasta llegar a la Ars brevis de 1308. Nos encontramos, por tanto, con que Llull, a partir del momento en que inicia su actividad «misionera», manifestará una enorme preocupación por delimitar y definir en una serie de obras axiales, cada vez de manera más específica y perfeccionada, las bases teóricas del sistema lógico de su pensamiento. El orgullo con que el propio Llull expone que el hallazgo de los mecanismos de funcionamiento de su Ars le vino dado a causa de una revelación divina experimentada en la montaña de Randa muestra su decidida voluntad de justificar la validez universal de su sistema.

Por medio de la lógica que propone en las diferentes versiones del Ars, Llull aspira a ofrecer unas reglas combinatorias gracias a las cuales el ser humano pueda explicar prácticamente cualquier cosa con vistas al establecimiento de la verdad. Se puede decir que toda la práctica de la escritura luliana pivotará en torno al sistema del Ars, que se constituirá por ello en su base significativa, formal y metodológica. Las obras lulianas no específicamente artísticas no serán en realidad más que aplicaciones prácticas de los principios allí expuestos.

Desde una perspectiva filosófica, Llull propugna en realidad un mundo acabado donde todo tiene un sentido claro y donde la carencia, la privación o el 
pecado surgen solamente como consecuencia de la falta de voluntad, por parte del ser humano, de obedecer a los requisitos y las exigencias de la primera intención. Heredero de la tradición de pensamiento y espiritualidad agustiniano-anselmiana, y próximo en diversos puntos a las tesis de su contemporáneo San Buenaventura, el sustrato ideológico de Llull es en realidad enormemente tradicional, si lo comparamos con el innovador maridaje de agustinismo y aristotelismo que Santo Tomás de Aquino posibilitó en el mismo siglo XIII (cf. Trías Mercant 1969: 18-20). Sin embargo, si el contenido de su filosofía es hasta cierto punto previsible, no lo es tanto la forma ni los procedimientos. Las figuras gráficas propuestas por Llull, su sistema de combinación protoalgebraica en que ciertas letras designan constantes significativas que permiten una expresión más mecanizada y simplificada de principios lógicos básicos, constituyen una novedad metodológica que cuenta, además, con el beneficio de un indiscutible rigor objetivo. Además, las relaciones conceptuales que el Ars hace explícitas configuran el sólido tejido en que Llull fundamentará el esquema del resto de sus obras.

De aquí se derivan una unidad y una circularidad evidentes en el pensamiento luliano. Porque, si bien las versiones del Ars fueron muchas y el resto de su producción escrita fue enormemente variada, incluyendo compendios de exempla, sermones, textos poéticos, místicos y un largo etcétera, en todas sus obras se puede apreciar una preocupación recurrente en torno a los mismos temas y estrategias formales y conceptuales, siempre al servicio de un único propósito: el de la persuasión. Aunque la producción de Llull presenta múltiples facetas, bien podría decirse, figuradamente, que en realidad no hizo más que escribir, de manera progresiva, un único libro, al servicio de una única intención. Un «libro» que, sin duda, él confiaba que, no por méritos propios sino por los de aquél que se los inspiraba (como ya manifiesta humildemente en el mismísmo Llibre de contemplació), podría llegar a convertirse en el mejor del mundo.

Desde esta perspectiva, no debe sorprender la diversidad de "géneros» practicados por Llull. En un sistema de referencias en que todo gira en torno a la consecución de la primera intención, a la fijación y establecimiento de los mecanismos necesarios para asegurar su cumplimiento y a la demostración del carácter intrínsecamente bueno y justo de la ordenación del mundo, a imagen y semejanza de la bondad, la grandeza, el poder y demás virtudes de Dios (cuya sustantividad indiscutible se establece como base y origen de todo lo creado), importa más el hecho de dejar constancia de esto último que el cómo se haga. En función de sus intereses e incluso del público al que se dirija, Llull cambiará la forma e incluso el tono de sus escritos. ${ }^{2}$

2 A esto hay que añadir, además, el hecho de que las fronteras genéricas en el siglo XIII no estaban tan bien delimitadas como ahora. El concepto mismo de literatura, tal como lo entendemos hoy en día, carecía entonces de formulación. En palabras de Lola Badia: «de literatura a Europa en sentit modern, als segles XIII i XIV no n'hi havia pas: els diversos gèneres romànics, dels lírics, als èpics, als narratius, eren segurament allò que més se li assemblava, però no eren precisament vistos pels seus autors $\mathrm{i}$ consumidors com a constitutius d'un cos textual autònom i nacionalment significatiu. Recordem que a la baixa Edat Mitjana predominava àmpliament la idea que la poesia el terme literatura hem quedat que no existia - no és altra cosa que l'embolcall de la veritat. No hi ha 
Pondremos un ejemplo claro que permitirá ilustrar lo que acabamos de decir. Algunos estudiosos se han preocupado de dilucidar si es justo atribuir a Llull el papel de precursor del diálogo religioso. En efecto, una obra como el Llibre del gentil e dels tres savis, donde un pagano y tres miembros de cada una de las religiones monoteístas discuten y ofrecen argumentos en un plano de igualdad, puede dar a entender que el talante de Llull era sorprendentemente conciliador y ecuménico. Sin embargo, el Llibre de meravelles mismo, escrito en París entre 1287-1289, insiste con frecuencia en la necesidad de predicar a los infieles sarracenos hasta la propia muerte, si es preciso, y otros textos de Llull llegan incluso a propugnar la conveniencia de las cruzadas al servicio del catolicismo. El problema se simplifica si interpretamos que se trata, en realidad, de estrategias diferentes que Llull considerará aptas en función de las características particulares de cada momento y de cuáles sean los destinatarios de sus textos. En cualquier caso, el propósito sustancial de persuasión en beneficio de la fe cristiana se mantiene siempre intacto en todos ellos. Ya lo observó, en una fecha tan temprana como 1957, Rubió i Balaguer:

¿Per què Ramon Llull, tan donat a una sola dèria, va vestir-la de maneres tan diferents? Tal vegada per la gran receptibilitat que tenia per als ambients que el voltaven, i per la voluntat que posava a adaptar-s'hi per tal de captar-los a les seves finalitats (Rubió i Balaguer 1985b: 265).

Éste es precisamente uno de los rasgos más originales y sorprendentes de la obra de Llull: la diversidad de registros que presentan sus obras, combinada al mismo tiempo con la relativa homogeneidad de sus contenidos. En esta misma línea, se ha valorado mucho, y con justicia, la figura de Llull por ser uno de los pioneros en la escritura filosófica y teológica en una lengua romance, que se añade a su abundante producción latina e incluso a algunos escritos en árabe, de los cuales desgraciadamente no conservamos ningún manuscrito. Todavía en la segunda mitad del siglo XIII, la originalidad del Blaquerna por su condición de protonovela romance (término discutible, pero que no entraremos a valorar ahora con el detalle que merece) resulta un elemento de indudable valor en la historia literaria del Occidente medieval.

Sirva, por tanto, esta breve introducción (en la cual no nos queremos extender innecesariamente, dado que todo lo antedicho se puede verificar de manera más consistente y con mayor profusión de detalles en otros textos críticos) para dar noticia de la originalidad expresiva de Llull, no tanto porque los materiales de pensamiento que pone en juego sean esencialmente novedosos, sino por el ingenio de que hace gala a la hora de combinarlos de manera eficaz al servicio de una causa bien definida, establecida en torno a unos sólidos parámetros lógicos que tienen como única finalidad la demostración y la celebración de la grandeza y la bondad divinas.

text literari, doncs, sense ficció, ni ficció digna de ser tinguda en compte sense un pòsit ocult d'autenticitat. Totes aquestes coses l'Edat Mitjana les havia heretades de la tradició neoplatònica i les havia anades reforçant a base de llegir $\mathrm{i}$ interpretar el llibre per antonomàsia, la Bíblia» (BADIA 1992: 76). 


\section{Una aproximación a la noción de exemplum en la obra luliana}

\section{Prácticamente al comienzo del Arbre exemplifical, Ramon Llull escribe lo siguiente:}

[...] e per los exemplis que darem pot hom haver doctrina a conèixer los secrets naturals e sobre natura, e a preïcar e a haver moralitats bones e solaç e amistat de les gents. E encara, en pot hom haver universal hàbit a entendre moltes coses plaents a entendre e plaents a oir.

Los exemplis que proposam donar volem departir en dues parts, ço és a saber, en recontaments e proverbis encercats segons les natures dels arbres; e aquest procés proposam tenir en aquest arbre. [...] abreujadament d'aquest arbre parlar volem; emperò, segons ço que direm, doctrina darem com hom se pusca haver a atrobar novells proverbis e novells recontaments, e estendre son enteniment per la gran matèria d'aquest arbre ( $O E$ II, 799).

Para valorar adecuadamente este fragmento, conviene tener en cuenta la singularidad del Arbre exemplifical en el conjunto de la producción luliana. Este «árbol» es uno de los dieciséis que componen el Arbre de ciència, magna enciclopedia escrita por Llull entre septiembre de 1295 y abril de 1296, en un tiempo récord de poco más de medio año. ${ }^{3}$ En los catorce primeros árboles, Llull trata con detenimiento, punto por punto, los diferentes niveles en la escala del ser, desde el que corresponde a los cuatro elementos hasta la esfera de la divinidad. De este modo, tenemos los árboles siguientes: elemental (sobre la naturaleza y las propiedades de las cosas elementales), vegetal (sobre las plantas), sensual (sobre los sentidos y la percepción), imaginal (referido a las impresiones suscitadas por la imaginación), humanal (ámbito propio del ser humano), moral (en que se habla de las virtudes y los vicios), imperial (en que se trata del ejercicio de poder propio de los príncipes), apostolical (referido al ejercicio episcopal o papal), celestial (ámbito de lo celeste, que influye asimismo sobre las cosas terrenales), angelical (referido a los ángeles), eviternal (donde se tratan temas relativos al paraíso y al infierno), maternal (referido a la Virgen María), cristianal (referido a Jesucristo) y divinal (referido a Dios y sus obras). Sin embargo, al final del libro Llull añade dos árboles más que no tienen tanto que ver con la escala del ser en sí misma como con ciertas técnicas básicas de comprensión y argumentación por analogía de los principios expuestos anteriormente: se trata de los árboles ejemplifical y cuestional. El primero de ellos, como se puede deducir de las líneas que hemos reproducido más arriba, se propone ofrecer un inventario de pequeñas narraciones que sirvan como refuerzo y ejemplificación de los contenidos de los catorce árboles iniciales y de modelo para la confección de otras narraciones de nueva planta; el árbol cuestional expone la técnica que hay que seguir en la formulación y resolución de

${ }^{3}$ Para conocer con detalle la estructuración de la obra, sobre la cual consignaremos aquí tan sólo unos breves apuntes, resulta aconsejable la lectura de BONNER (2002). Asimismo, se puede localizar una práctica representación gráfica de los contenidos temáticos de los dieciséis árboles en Cruz Hernández (1977: 127-143). 
todo tipo de preguntas planteadas en relación con las materias tratadas en aquellos mismos catorce árboles.

No resulta difícil comprobar que el uso de los exempla aparece aquí intimamente al servicio de la (de)mostración de una concepción jerárquica y organizada de todo cuanto existe. Aragüés Aldaz ha observado, con buen criterio, que «la concepción tradicional de un universo ordenado y jerárquico, en el que cada plano de la Creación refleja el mismo original divino, según la conocida idea de la escala del ser, explicaba la utilidad, entre todas las variedades de la literatura, de aquellas formas metafóricas que ilustran, por vía analógica [...], las realidades sobrenaturales a partir de las descripciones de una naturaleza sentida como libro eterno o imagen y símbolo de Dios» (Aragüés Aldaz 1996: 299; los subrayados son nuestros). Más allá de las conclusiones específicamente literarias a que estos procedimientos de relación analógica nos puedan llevar, creemos que éste es un punto esencial para comprender la cosmovisión luliana en su conjunto. Tal como manifiesta paradigmáticamente el título de otra obra decisiva de Llull, el Liber de ascensu et descensu intellectus, el hombre puede acceder intelectualmente a la comprensión de la verdadera ciencia sobrenatural siguiendo un proceso inductivo o de ascenso del entendimiento, es decir, partiendo de los indicios que le proporcionan las cosas de este mundo, dado que en ellas es posible apreciar las «semejanzas» (semblances) de las dignidades divinas (bondad, grandeza, eternidad, poder, sabiduría, virtud, verdad, gloria, perfección, justicia, misericordia...); asimismo, puede seguir el proceso inverso de deducción, que le permitirá reconocer los elementos de la creación como operación y manifestación de las dignidades divinas. Leamos, por ejemplo, el versículo siguiente del Llibre d'amic e amat:

\section{[57]}

Demanaren a l'amich:-Quals són tes riquees?

Respòs: - Les pobretats que sostench per mon amat.

-E qual és ton repòs?

-Lo languiment que $m$ dóna amor.

-E qui és ton metge?

- La confiança que he de mon amat.

-E qui és ton maestre?

Respòs e dix que les significances que les creatures donen de son amat.

(Llull 1995: 83-84; el subrayado es nuestro).

Resulta evidente, por tanto, que los procedimientos analógicos que se constituyen como razón de ser básica del exemplum luliano no son un mero artificio literario, sino que son manifestación práctica de una determinada concepción del mundo. Desde esta perspectiva, el exemplum tiene una función utilitaria, ya que es un medio para hacer explícitas las relaciones en la escala del ser que, de otro modo, permanecerían ocultas a nuestro entendimiento. Su papel es doble: pedagógico y rememorativo. Así, en el fragmento del Arbre exemplifical que hemos citado más arriba, el propio Llull manifiesta que por medio de los exempla 
que dará «pot hom haver doctrina a conèixer los secrets naturals e sobre natura, e a preïcar e a haver moralitats bones e solaç e amistat de les gents» (el subrayado es nuestro). ${ }^{4}$ Asimismo, decimos que el exemplum luliano es rememorativo porque permite actualizar en la conciencia las relaciones existentes entre los diferentes niveles de la creación; esta actualización será tanto más efectiva cuanto mayor sea el esfuerzo intelectivo que el exemplum exija al lector, de acuerdo con el conocido fragmento del libro segundo del Fèlix:

—Sényer - dix Fèlix al sant ermità-, molt me meravell de vostros eiximplis, car vijares m'és que no facen res al prepòsit de què jo us deman.

—Bells amics —dix lo ermità-, escientment vos faç aitals semblances per şo que vostro enteniment exalcets a entendre; car on pus escura és la semblança, pus altament entén l'enteniment qui aquella semblança entén (OS II: 72; el subrayado es nuestro).

Sin embargo, llegados a este punto, conviene hacer una distinción, porque este carácter utilitario al que aludimos en la obra luliana no es exclusivo del exemplum, sino que se extiende a otras formas breves. De hecho, en el texto del Arbre exemplifical que hemos transcrito anteriormente se habla indistintamente de exemplis, proverbis y recontaments. Si echamos un vistazo general al Arbre exemplifical, podremos apreciar que, junto a los exempla (recontaments) de estructura más o menos prototípicamente narrativa, se pueden hallar asimismo proverbios sintéticos, que parecen eludir cualquier desarrollo narrativo extenso. El hecho de que Llull no haga aquí una distinción apriorística clara entre ambas modalidades muestra que, para él, ambas comparten idéntico carácter utilitario y que, si bien presentan diferencias en cuanto a la forma, son aplicables a un mismo propósito comunicativo.

La confusión terminológica se hace también evidente en el Llibre d'Evast e Blaquerna, donde Miguel Arbona (1976: 56) ha identificado varios términos relacionables con la esfera narrativa de los exempla. Según Arbona, Llull parece emplear indistintamente, en varias ocasiones, las palabras exempli y semblança. Por otra parte, Araguiés Aldaz advierte que aun el mismo término exempli, por sí mismo, presenta «un sentido amplio, válido para cualquier comparación argumentativa»; es utilizable no sólo en un sentido específico, sino también en un sentido más general, ajeno a cualquier consideración retórica (Aragüés Aldaz 1996: 304-305). Asimismo, explica que «el proverbi en el Arbre exemplifical posee una relativa complejidad argumental, derivada de la presencia de un incipiente dialogismo, similar en gran medida al de los relatos. A todo ello, quizá, pueda atender la extensión de un rótulo como exempli a dichas secuencias en el

4 Hallamos una clara muestra de este carácter pedagógico del exemplum luliano en el capítulo tercero del Blaquerna, en que Evast plantea una cuestión a su hijo para ponerle a prueba y conocer si podrá responder con eficacia a problemas concretos y si su proceso gradual de formación e instrucción ha sido adecuado; a tal efecto, suscita el desarrollo de un exemplum que Blaquerna será finalmente capaz de llevar a una feliz consecución. De este modo, se verifica que la mejor manera de demostrar la asunción intelectual de un problema y de responder a él juiciosamente consiste en saber aplicar a su debido tiempo los exempla pertinentes. 
Arbre exemplifical» (Araguiés Aldaz 1996: 306). Albert Hauf, en referencia a esta misma obra, ha escrito que «la divisió que fa Llull dels seus exempla en dues parts: els prouerbia i els racontaments [...], prova que la interacció i fins i tot confusió - seria el cas de Llull i de D. Juan Manuel - entre allò que hom denomina «Kleinstformen der Literatur», ${ }^{5}$ o sigui les dites o sentències, $\mathrm{i}$ les contarelles o històries breus, és volguda i deliberada» (Hauf 2002a: 307), mientras que, en opinión de Rubió i Balaguer (1985b: 290): «Tots aquests elements que poden encloure una moralitat o un ensenyament, ja siguin de forma sentenciosa, dogmàtica, al·legòrica o simplement imatjada, eren per a Ramon Llull recursos d'igual finalitat en la pràctica, encara que en el seu tractat de retòrica els distingeixi» (Rubió i Balaguer 1985b: 290). Aquí Rubió se está refiriendo a un volumen decisivo para valorar la estética literaria de Llull, la Rhetorica nova, al cual nos referiremos más adelante.

En realidad, el dilema se simplifica si, en la línea de lo que exponíamos en el apartado anterior, valoramos la diversidad de formas y denominaciones de la producción escrita luliana en función del eje central que la sostiene y da sentido: el Ars. Porque, en definitiva, "Llull converteix els exempla en un mecanisme apodíctic subordinat a la seva Art», como bien ha observado ya Josep-Antoni Ysern (1999: 48). Además, esta consideración vale no sólo para los exempla, sino también para otras formas «literarias» practicadas por Llull. Por ejemplo, Lola Badia remarcó en su momento que «els fragments de discurs doctrinal que Llull anomena sermons, en puritat no són homologables amb allò que la tradició designava amb aquest nom. Són sermons «artístics». Ja ho anuncia el beat al pròleg del Liber de Praedicatione mateix, quan diu que el fa per tal que (tradueixo) «qualsevol predicador fâcilment pugui "trobar" per ell mateix qualsevol sermó de qualsevol matèria amb el supòsit que conegui les coses que es contenen en l'Art [general]»» (Badia 1992: 90). La propia Badia remarca con sorpresa que los sermones integrados por Llull en el Liber de Virtutibus et Peccatis/Art major de predicació contaban con una peculiaridad del todo inhabitual en el formato tradicional de sermón del momento: carecían de thema bíblico (Badia 1992: 90). Si tenemos en cuenta el carácter ortodoxo de Llull desde el punto de vista religioso, concluiremos que esta peculiaridad sólo puede deberse a su convicción profunda de que el Ars era válido por sí mismo para constituirse en base de cualquier razonamiento persuasivo, incluido el sermón, por convencionalizada que estuviera su estructura.

Nuevamente Rubió i Balaguer pone el dedo en la llaga al apreciar que «els exemples lul-lians són ben diferents dels que solen trobar-se als repertoris medievals. No n'hi ha de vides de sants i poden comptar-se amb els dits els derivats de la història profana. En canvi, són nombrosos els procedents de llibres d'apòlegs orientals (com els del Llibre de les bèsties que tindrien llur font al Calila), bestiaris o els que tal volta deriven dels llibres sobre les propietats de les herbes o dels metalls. [...] Un altre grup el formen els veritables exemples amb desenrotllament més folgat, que de vegades semblen contes en miniatura [...]. D'aquest caràcter són molts dels que llegim al Fèlix i també al Blanquerna» (Rubió

\footnotetext{
5 Cf. Haug / Wachinger (1994).
} 
i Balaguer 1985b: 291-292). Por tanto, Llull hace en realidad una reelaboración bastante personal de los recursos folklóricos y ejemplarísticos que le ofrece la tradición literaria, adaptándolos de la manera más efectiva a sus propósitos de persuasión. Ysern, que recoge estas mismas observacions de Rubió, advierte que, de hecho, «tot i que el Fèlix sigui un autèntic enfilall d'exempla, els resultats de qualsevol investigació adreçada a esbrinar-ne les fonts, a força de recórrer als repertoris més importants d'exempla homilètics, serien ben migrats» (Ysern 1999: 49).

A esto se añade otro rasgo innovador característicamente luliano: si echamos un vistazo a los exempla del Arbre exemplifical, no tardaremos en advertir las peculiares condiciones de «irrealidad» $\mathrm{o}$ «virtualidad» de muchos de sus actantes. Además de los exempla protagonizados por personas o por personificaciones de animales, Hauf (2002a: 324) identifica otros donde intervienen personificaciones de tiempos verbales, figuras geométricas, piedras y metales, instrumentos y objetos diversos, los elementos corporales del hombre con sus diferentes partes y sentidos, el alma humana y sus potencias, los planetas y varios elementos directamente extraídos de la teoría artística luliana, como por ejemplo las dignidades divinas, los principios correlativos, sujetos, vicios, virtudes y los cuatro elementos.

En definitiva, resulta obvio que Llull se resiste a ser encorsetado en categorías demasiado rígidas, ya que siempre barre para casa y, o bien adapta libremente materiales preexistentes, o bien no tiene reparos en idear narraciones novedosas a partir del establecimiento de inesperados vínculos analógicos entre elementos que a menudo presentan un alto grado de abstracción y que siempre son puestos en relación de acuerdo con alguno o varios de los principios combinatorios básicos previstos en el Ars. Al fin y al cabo, tal como ha afirmado Jordi Gayà (1980: 64), la forma literaria luliana no es más que una forma del Ars luliana. $^{\text {? }}$

' En Aragüés Aldaz (1999) se puede encontrar un seguimiento exhaustivo de la evolución teórica que experimenta la noción de exemplum desde las preceptivas de la antigüedad clásica hasta los Siglos de Oro de la literatura castellana, pasando naturalmente por la época medieval. Las informaciones que aporta son de gran utilidad para el estudioso de la literatura ejemplarística en general, pero su aplicación concreta a la producción escrita de Llull resulta siempre conflictiva, dada la originalidad del escritor mallorquín.

7 En relación con lo que acabamos de exponer, querríamos hacer mención de un par de artículos clásicos de Robert D. F. Pring-Mill, puesto que tuvo el mérito de ser uno de los primeros en proponer una lectura de la obra de Llull a partir de su grado de relación con los presupuestos teóricos del Ars luliana (aunque después de que Rubió i Balaguer (1985b) hubiese advertido juiciosamente que la noción de expresión literaria luliana sólo tenía sentido si era valorada en tanto que medio divulgativo de los principios del Ars). En uno de dichos artículos, Pring-Mill (1991a) estudió los vínculos existentes entre el primer exemplum de la sección de las raíces del Arbre exemplifical y la teoría de los cuatro elementos, comúnmente aceptada en el siglo XIII (e incorporada, de hecho, como elemento integrante de las primeras versiones del Ars), y sostuvo la tesis de que, por medio de exempla como el analizado, Llull en realidad transmutaba la ciencia en literatura; dicho de otro modo, daba una expresión literaria a elementos significativos procedentes del ámbito de la ciencia medieval. En el otro artículo (1991b), más valioso si cabe, Pring-Mill hizo un estudio de uno de los versículos del Llibre d'amic e amat a partir de conceptos extraídos del Ars luliana. En nues- 
Todo lo que acabamos de decir motiva que la caracterización de exemplum que propusieron Claude Bremond, Jacques Le Goff y Jean-Claude Schmitt en la Typologie des sources du Moyen Âge occidental no se ajuste plenamente al caso luliano. Según estos autores, el exemplum medieval sería «un récit bref donné comme veridique et destiné à être inséré dans un discours (en général un sermon) pour convaincre un auditoire par une leçon salutaire» (Bremond / Le Goff / Schmitt 1982: 37-38). Hasta aquí no encontramos excesivos problemas. Sin embargo, una de las propiedades características del exemplum sería «la veracité ou l'authenticité, c'est-à-dire que le récit rapporté dans l'exemplum est, toutes les fois qu'il est possible, affirmé comme historique, comme s'étant réellement passé ou, dans le cas de l'exemplum animalier, comme possédant les qualités de ce qui s'est réellement passé» (Bremond / Le Goff / Schmitt 1982: 37; los subrayados son del original). ¿Podríamos aplicar esta propiedad a los exempla del Arbre exemplifical? En nuestra opinión, se trata de una cuestión de grado: para Llull, todos los componentes de la creación son relacionables por vía analógica, y el resultado que de estas relaciones se deriva tiene validez probatoria en tanto que reflejo de la verdad ontológica de todo cuanto existe por voluntad divina. Por tanto, difícilmente sus ejemplos podrían ser calificados de «no veraces» o «no auténticos», ya que en realidad su validez viene dada por el estable referente que señalan. Es precisamente a causa de la estabilidad de ese referente ontológico que cualquier tipo de «semejanza» que consiga dar cuenta de él analógicamente será, desde la lógica luliana, plenamente justificable, por más que los procedimientos empleados en la confección de los exempla puedan resultar poco habituales desde la perspectiva de la convención literaria. Sea como fuere, como bien ha valorado ya Ysem (1999: 50), no es desacertada la definición de exemplum luliano que propone Arbona en su estudio sobre el Blaquerna: «Breve realización o narración de un hecho, del que más o menos inmediatamente se desprende alguna significación que, o bien se da por sabida o bien se expone, o bien se solicita por medio de una pregunta, con la finalidad de iluminar el entendimiento sobre alguna verdad o decidir a la voluntad sobre algún proceder; todo ello de la manera más apta para captar la atención por medio del ingenio o de la sorpresa y para lograr una emoción en la que se apoye la convicción o la decisión" (Arbona 1976: 59; el subrayado es nuestro). Esta propuesta de definición presenta, además, una doble ventaja. En primer lugar, da cuenta de que, en la producción escrita luliana, buena parte de los exempla (y de ciertas formas epigramáticas, a las que Llull era tan aficionado) requieren de una «exposición» clarificadora que permita constatar la correcta asimilación de su contenido y redunde en un aumento efectivo de conocimiento intelectual. Es lo que Llull expresa en el capítulo 99 del Blaquerna, previo a la sucesión de versículos del Llibre d'amic e amat, cuando escribe lo siguiente:

tra modesta opinión, muy pocos estudiosos (con algunas excepciones notables, como por ejemplo la aportación de Hauf (2002a), a la cual podríamos añadir otros intentos, como el de Cabré / Ortín / Pujol (1988)) se han propuesto un análisis sistemático del grado de emparentamiento de muestras diversas de la producción escrita luliana con el sistema ideológico que constituye en realidad su soporte básico. No dudamos de que un trabajo de este tipo aplicado con exhaustividad al corpus de exempla lulianos de que disponemos sería muy clarificador de cara al discemimiento del poderoso alcance significativo de las técnicas expresivas empleadas por su autor. 
Dementre considerava en esta manera Blanquerna, ell remembrà com una vegada, com era apostoli, li recomptà un sarraí que los sarraïns han alcuns hòmens religiosos, e, enfre los altres e aquells qui són més preats enfre ells, són unes gents qui han nom «sufies», e aquells han paraules d'amor e exemplis abreujats e qui donen a home gran devoció; e són paraules qui han mester esposició, e per l'esposició puja l'enteniment més a ensús, per lo qual pujament muntiplica e puja la volentat en devoció (LLULL 1998: 273-274; el subrayado es nuestro).

La segunda ventaja de la definición de Arbona es que hace referencia al efecto de sorpresa que Llull pretende suscitar en el receptor de sus exempla. Pero para que esta sorpresa sea posible, el receptor ha de tener una disposición previa a dejarse interpelar por los aspectos aparentemente contradictorios de la realidad. La capacidad de meravellar-se resulta nuclear en la obra luliana, ya que, según Júlia Butinyà (1996: 94):

A l'home, doncs —sembla haver-hi entès Llull-, li ha d'estranyar tant el mal (primer problema que es planteja Fèlix, i també el gran drama del gentil lul.lià; com a injustícia en el primer i sota la idea de mort en el segon) com el bé (la vida i la creació). Llull manifesta que li ha d'horroritzar el mal -a l'igual que fa Job-; però també que l'ha de copsar el bé. Instaura, per tant, l'actitud de perplexitat, d'estranyament davant una cosa i l'altra. Com si es tractés d'un estat de revolució contínua».

No en vano, uno de los componentes fundamentales que mueven a Fèlix a querer profundizar cada vez más en el conocimiento epistemológico de todo lo creado es su relativa facilidad para meravellar-se de todo cuanto le rodea. La capacidad de asombro favorece la reflexión intelectual encaminada a la resolución de las cuestiones contradictorias que llegan a nuestra conciencia (por expresarlo en términos actuales); una vez obtenida esta resolución, el ser humano aumenta sus conocimientos y dispone de nuevos datos en los que apoyarse psicológica y afectivamente. Las ganancias en este proceso son tan apreciables que, cuando las circunstancias no aportan datos suficientes que induzcan a la meravella, todavía es posible suscitarla, con vistas a la eliminación de las creencias erróneas o a la corrección de comportamientos poco virtuosos. En este sentido, Hauf (2002a: 313) ha observado que, en el Blaquerna, los personajes de Ramon lo Foll y el Joglar de Valor recurren a provocaciones «escénicas» con la finalidad de motivar la sorpresa del resto de personajes; éstos, extrañados, les preguntarán por la razón de tan inesperada conducta para deshacer la incertidumbre, circunstancia que aprovecharán aquéllos para enunciar el exemplum pedagógico apropiado.

Líneas más arriba hemos hecho mención de la Rhetorica nova, texto luliano escrito en catalán, presumiblemente en 1301, del cual sin embargo sólo hemos conservado una copia latina de 1303. Se trata de un texto fundamental para establecer rasgos decisivos de la concepción literaria de Ramon Llull, a pesar de haber sido elaborado como manual de indicaciones para la confección de sermones «a la manera luliana», más que como un tratado retórico stricto sensu. 
En relación con la cuestión terminológica señalada anteriormente, llama la atención constatar que en la Rhetorica Llull sí que establece una diferenciación entre exemplum y proverbium, aunque ésta se limite a cuestiones meramente formales (como por ejemplo la observación de que el proverbio se caracteriza por ser una breve proposición de carácter sentencioso), ${ }^{8}$ más que de tipo específicamente utilitario. Además, Llull identifica en esta misma Rhetorica dos tipos diferentes de exempla: los exempla naturalia y los exempla moralia. Los primeros ilustran el mundo moral a partir de la puesta en relación de cualidades de la naturaleza, y pueden referirse a entidades espirituales (Dios y los ángeles) o corporales (el cielo, la tierra, los propios animales), mientras que los segundos se disponen en torno a las virtudes o los vicios, y en ese caso sus temas pueden ser concordantes (cuando se refieren únicamente a las virtudes) o de contrariedad (cuando se refieren al mismo tiempo a vicios y virtudes, que establecen entre sí relaciones de oposición $)^{9}$.

Esta última distinción que acabamos de señalar se articula en función de rasgos significativos o semánticos, más que formales. Esto demuestra hasta qué punto Llull se aleja de cualquier tipo de prescripción retórica tradicional. Sin embargo, su punto de vista es perfectamente coherente con la original teoría del ornato retórico que hace explícita en la Rhetorica nova e incluso en otras obras. Como ya hemos indicado, para Llull la forma se subordina siempre a lo sustancial y necesario, de manera que no resulta posible concebir la posibilidad de un discurso bello si no se erige como expresión de una realidad significativa igualmente bella y esencialmente verdadera. La belleza retórica ha de estar subordinada a la eficacia comunicativa.$^{10}$ El ornato por sí mismo carece de valor; por ello, según leemos en la Rhetorica, la mejor manera de hacer bellas comparaciones (porque no olvidemos que Llull basa su técnica narrativa en la aplicación permanente de la analogia entis) es el uso de la vox significativa. ${ }^{\prime \prime}$

Hallamos aquí verbalizado, por tanto, un rasgo fundamental de la estética «literaria» de Llull: cualquier texto escrito, y subsiguientemente cualquier forma narrativa breve que pueda emplearse, carecen de sentido tomados únicamente en cuanto tales, y sólo son válidos en la medida que adquieren una significación estable por su condición de reflejo analógico de lo existente. De este modo se explica, tal como ya advirtió, no sin estupor, Rubió i Balaguer en su momento (cf.

${ }^{8}$ Citamos por la reciente edición de la Rhetorica nova a cargo de Jaume Medina: «Prouerbium est sermo breuis magnam in se sententiam continens. [...] ipsum prouerbium est uerborum introductio, loquenti audaciam et consilium conferens» (ROL xxx: 49-50).

${ }^{9}$ «Pulchra exempla sunt ex duplici materia, quia uel sunt de rebus naturalibus aut de rebus moralibus. Res autem naturales aut sunt spirituales, ut Deus et angeli, aut corporales, ut coelum, terra, animalia. Similiter res morales sunt duplices, quia aut uirtutes, aut sunt econtra uitia et peccata. Cum igitur ita sit, si ille qui loquitur uoluerit quod uerba sua sint placibilia et decora, debet de praedictis exempla sumere, et ad uerba sua ordine debito applicare» (ROL xxx: 36).

10 «verba sint utilia, quia quae utilitate sunt uacua non poterunt esse pulchra. [...] finis sit possibilis, ad quem uerba fuerint applicanda» (ROL XXX: 58$)$.

1 Por otra parte, conviene no olvidar que Llull ofrece de manera precisa en el Ars los procedimientos óptimos para el establecimiento de comparaciones eficaces, ya que la figura $\mathrm{T}$ o de las significaciones incorpora la tríada de relaciones diferencia-concordancia-contrariedad. 
1985a: 220), que oraciones aparentemente aceptables como «regina et ancilla sunt pulchrae» $\mathrm{O}$ «pulchra est regina» resulten inadmisibles para Llull; en el primer caso, porque comparar personajes de rangos sociales tan distintos constituye una indecencia, y en el segundo, porque la anteposición del adjetivo en el orden de la oración supone un rebajamiento de la dignidad debida al sustantivo, que por ser la palabra más importante merece situarse en primer lugar (cf. los fragmentos correspondientes en la sección «De pulchris comparationibus» de la Rhetorica nova (ROL XXx: 34-36)).

Esto demuestra, en definitiva, la homología que la idiosincrásica cosmovisión luliana establece entre el dominio de lo ontológico y el dominio de lo verbal. ${ }^{12}$ Para Llull, las formas expresivas más apropiadas serán aquellas que den cuenta con la mayor precisión del carácter positivo que reviste el fundamento ontológico de todo lo creado, y su última finalidad, no lo olvidemos, está al servicio de la primera intención: conocer, amar y servir a Dios.

\section{Breve comentario de los exempla del capítulo 62 del Llibre de meravelles. Observaciones sobre la dualidad vida activa / vida contemplativa}

Las observaciones que hemos formulado en los apartados anteriores pretenden contribuir modestamente a la comprensión teórica del papel que juega el exemplum en la producción escrita luliana. En el apartado siguiente nos proponemos estudiar de forma práctica en qué grado el ejercicio de la escritura y, más concretamente, el uso de los exempla, sirven como vehículo para la explicitación de elementos significativos esenciales en el sistema de referencias luliano. Para ello nos centraremos en un capítulo concreto del Llibre de meravelles; nuestro recorrido por los diferentes exempla que lo conforman, que se articulan en torno a los conceptos de vida activa y vida contemplativa, nos servirá para comprobar cómo Llull subordina el empleo de cualquier modalidad expresiva o estilística al ámbito siempre sustantivo y apriorístico, de acuerdo con su particular concepción del mundo, de la significación.

El Llibre de meravelles se dispone en diez libros diferenciados, que tratan sucesivamente de Dios, los ángeles, el cielo, los cuatro elementos, las plantas, los metales, las bestias, el hombre, el paraíso y el infierno. A estas diez secciones se añaden un breve prólogo y un epílogo o conclusión. En la estructura misma del Llibre de meravelles, también conocido como Fèlix a causa del nombre de su principal protagonista, se evidencia nuevamente la preocupación de Llull por dar cuenta de un saber totalizador, que se ocupe de todas las escalas ontológicas posibles, análogamente a lo que sucede, aunque de manera todavía más desarrollada estructuralmente, en el Arbre de ciència. Como ha observado Llúcia Martín Pascual, el Llibre de meravelles es «una mena d'enciclopèdia de filosofia

12 No hacemos aquí sino reproducir las observaciones de Mark D. Johnston, quien en la introducción a su edición de la Rhetorica nova hace referencia a esta misma "homology between metaphysical and verbal order, which Llull proposes as the basis of all beauty in words and things» (Johnston 1994: xxii). 
natural, mitjançant la qual s'arriba al coneixement suprem de Déu, és a dir, al saber teològic» (Martín Pascual 2002: 27).

El prólogo proporciona el marco narrativo principal de toda la obra. Un buen hombre, entristecido por constatar «com Déus en aquest món ha tan pocs amadors e servidors e loadors», se dirige a su hijo Fèlix con estas palabras:

-Amable fill, quaix morta és saviea, caritat e devoció; e pocs són los hòmens qui són en la fi a la qual nostro senyor Déus los ha creat. No és la fervor ni la devoció que esser solia en lo temps dels apòstols e dels màrtirs, que per conèixer e amar Déus languien e morien. A meravellar te cové on és caritat e devoció anada. Ve per lo món, e meravella't dels hòmens per què cessen de amar $\mathrm{e}$ conèixer Déu. Tota ta vida sia en amar e conèixer Déu, e plora per los falliments dels hòmens qui Déus ignoren e desamen ( $O S$ II: 19-20).

Dicho y hecho. Fèlix se lanza por el mundo y se encuentra por el camino con diversas situaciones que le hacen meravellar-se, hasta el punto de que en más de una ocasión se siente tentado a poner en duda sus opiniones previas. Sin embargo, a lo largo de su trayecto aparentemente sin rumbo, va topando con diversos interlocutores que le permitirán reafirmarse en los postulados de la fe cristiana mediante la exposición de numerosos exempla pedagógicos. Fèlix, a su vez, se convierte en contador habitual de nuevos exempla por medio de los cuales expone por analogía sus puntos de vista y establece un diálogo interactivo con el interlocutor correspondiente. Cada una de las diez secciones que integran el Llibre de meravelles recoge diversos exempla relacionados con el ámbito temático específico que les da título.

Cabe adherirse a la opinión de Josep-Antoni Ysern cuando afirma que el Llibre de meravelles «es caracteritza, més que més, per: a) L'existència d'una acció - més o menys esquifida - exterior a la conversa exemplar. b) La circulació bidireccional dels exempla [...]. c) Endemés, la complexitat de certes narracions, aprofundeixen [sic] aquest esquema amb exempla de vegades concèntrics» (Ysern 1999: 51). Por otra parte, en relación a la naturaleza misma de los exempla, Martín Pascual se expresa en los siguientes términos:

Els exemples [del Llibre de meravelles] poden ser de tres tipus: experiències viscudes pel protagonista i que es confonen amb la història-marc [...]; visió d'escenes que ocorren davant del protagonista [...], i, la gran majoria, exemples narratius producte del diàleg entre Fèlix i el savi de torn (Martín Pascual 2002: 26).

A estas apreciaciones se añade la peculiaridad que supone, en el conjunto del Llibre de meravelles, el Llibre de les bèsties, cuya interpolación, según Pere Bohigas, es evidente dado su carácter autónomo, que difiere del enfoque narrativo seguido en el resto de secciones del Fèlix:

Mentre que en els altres llibres Fèlix, a semblança d'un cavaller, «anava per los boscatges, per munts e per plans, e per erms e per poblats, e per prínceps e per cavallers, per castells, per ciutats, e meravellava's de les meravelles qui són en 
lo món, e demanava ço que no entenia, recontava ço que entenia», en el Llibre de les Bèsties Fèlix fa simplement d'espectador. Dos apostòlics que trobà anant de camí, li digueren que en una plana pròxima hi havia un aplec de bèsties salvatges que volien elegir rei. Fèlix s'hi encaminà i hi trobà els animals discutint quin d'ells farien rei» (Bohigas 1981: 8-9).

Bonner reordena algunos argumentos ofrecidos ya por el propio Bohigas al afirmar que el Llibre de les bèsties «és l'única obra de tota la seva producció on Llull empra tant de material pre-existent», y acto seguido añade:

I la naturalesa d'aquest material és interessant: a excepció del nom i caràcter del principal protagonista, pres del Roman de Renart francès, és tot d'origen oriental. Hi ha un conte del Libre dels set savis de Roma (també anomenat el Libre de Sindibad o Sendebar), un de Les mil $i$ una nits, i no menys que deu de l'aràbig Calila i Dimna, que té el seu origen llunyà en el Panxatantra de l'Índia (OS II: 12-13).

En suma, el carácter relativamente extraordinario del Llibre de les bèsties hace de él una obra bastante peculiar cuyos exempla, en cierta medida, no resultan tan innovadores, en cuanto a sus contenidos, como otros de factura específicamente luliana; y si bien es cierto que incluso en el Arbre exemplifical es posible identificar algún exemplum de inspiración claramente oriental (es el caso del «exempli de la branca imperial»), o que se pueden llegar a aventurar algunas analogías notables entre los procedimientos técnicos de desarrollo de los exempla del Arbre y los del Calila, como ha indicado Albert Hauf (2002a), hemos de reconocer que buena parte de los exempla lulianos sorprende precisamente por su carácter novedoso y por su dificultad de adscripción a formatos previos claramente reconocibles.

El capítulo 62 del Llibre de meravelles forma parte de su sección octava, «D'home», la cual, según refiere Trías Mercant (1969: 114), fue caracterizada por Éphrem Longpré, ya en una fecha bien temprana (1926), como una especie de interesante tratado de psicología. Se trata de la sección más extensa del libro, y en nuestra opinión es posible dividirla en tres partes:

a) La primera comprendería el fragmento que encabeza el libro y los capítulos 44-61, y daría cuenta de diferentes aspectos relacionados con el ser humano desde una perspectiva ontoteleológica. De este modo, los diferentes capítulos que la integran muestran qué es el hombre, para qué ha sido creado y cuál es la finalidad de sus atributos anímicos (las tres potencias del alma: memoria, entendimiento y voluntad) y corporales (los cinco sentidos, a los cuales Llull aún no ha añadido el affatus o «sisè seny», tema central de un libro posterior).

b) La segunda comprendería los capítulos 62-100 y se basaría en la contraposición de parejas de términos contrarios (entre los cuales se enumeran trece parejas de vicios y virtudes, junto con otras de conceptos de naturaleza más general), con la salvedad de los capítulos inicial (el 62) y conclusivo (el 100), en que los conceptos comparados (vida activa ver- 
sus vida contemplativa y libre albedrío versus predestinación) resultan contradictorios sólo en apariencia. ${ }^{13}$

c) La tercera comprende los capítulos 101-115; en ellos se tratan monográficamente conceptos diversos, buena parte de los cuales se relacionan con el ámbito de las virtudes y de los preceptos cristianos.

Una vez situado estructuralmente el capítulo de que nos queremos ocupar en el conjunto de la obra de que forma parte, podemos entrar de pleno a comentar sus características más significativas. ${ }^{14}$

A semejanza de lo que sucede en otros capítulos del Llibre de meravelles, el primer párrafo sintetiza la idea fundamental en torno a la cual se articulará el contenido de los exempla del capítulo. En primer lugar, el ermitaño con quien Fèlix está conversando advierte que la vida activa y la vida contemplativa pertenecen al estamento humano, con la finalidad de justificar la inclusión de este capítulo en la sección dedicada al dominio del hombre. Acto seguido, expone el tema principal, expresado en esta ocasión de forma proverbial o sentenciosa: «Vida activa està per necessitat, e vida contemplativa està per compliment».

Para valorar mejor el alcance de esta afirmación, puede resultar de utilidad consultar el capítulo 87 de la Doctrina pueril del propio Llull, escrita con anterioridad al Llibre de meravelles. Dicho capítulo trata también del tema de la vida activa y la vida contemplativa. Reproducimos a continuación los fragmentos siguientes, procedentes de la reciente edición de Joan Santanach i Suñol:

[2] Sapies, fil, que .III. carreres son a significansa de .II. vides: carrera juzana, miyana, subirana. La carrera juzana es de peccats; la migana es vida activa; la subirana es vida contemplativa. Hon, con la vida contemplativa sia pus prop a Deu e pus luny de peccats que la vida activa, per assó la vida comtemplativa es pus noble que la activa.

[3] En la carrera jusana son, fil, los homens peccadors, amadors d'aquesta vida mundana, per so que agen los delits temporals. On, aquels viuen quant a el cors, mas quant a l'anima moren en peccat e en colpa. E per assó, fil, no vages per aytal via que mena hom a mort perdurable.

[4] En la via migana son los homens qui an vida activa, so es a ssaber, los homes qui posseexen les benananses d'aquest mon per entenció que $n$ fassen be per la amor de Deu, e an muyer e infants e an los dalitz d'aquest mon ordonadament, los quals graexen a Deu e.n los quals esquiven obres de peccats. Hon, aytals homens an aquest mon e l'altra.

${ }^{13}$ El lector podrá hacerse una idea de la productividad que adquieren estas contradicciones aparentes en el sistema luliano tras consultar las observaciones aportadas por Ruiz Simon (1996) en torno a la dualidad predestinación-libre albedrío.

14 La edición en que nos hemos basado a la hora de efectuar nuestro comentario es la de Anthony Bonner (cf. OS II: 208-211). 
[5] En la vida contemplativa son los homens qui fan aspra vida e contemplen Deu ab dejunis, oracions, pobretat, contricció, meynspreament d'aquest mon; on, aquets hòmens, fil, an l'altra segla mils que-ls homens qui van per la via miyana. E saps per que? Per so cor donen aquest segla per l'altra e desemparen les benuyranses d'aquest mon (NEORL VII: 238-239).

En el texto de la Doctrina pueril, resulta obvio que la vida contemplativa es preferible a la vida activa, y no digamos a la vía pecaminosa que corresponde a la «carrera jusana». La vida activa consiste en administrar convenientemente los bienes temporales de que se dispone, al servicio siempre de la primera intención. La vida contemplativa es superior porque exige el desprendimiento de los bienes mundanos, que pueden interferir en el proceso de orientar por completo la propia voluntad a Dios y llegar a impedirlo. Para ajustarse a las exigencias de la vida contemplativa resulta necesario llevar una vida «áspera», caracterizada por la pobreza y por el ejercicio de una piedad ascética y penitente. Sin embargo, resulta obvio que es posible ser justo y mantenerse en la virtud por medio del ejercicio de la vida activa, aunque en ese caso los riesgos de ceder a la tentación de la vida «mundana» resulten mayores.

En el capítulo 39 del Llibre dels mil proverbis hallamos los proverbios siguientes:

4. Fé vida activa per ço que sia contemplativa.

5. Vida activa és per ço que sia contemplativa ( $O E$ I: 1264)

De aquí se deriva que Llull está lejos de desaconsejar la vida activa, e incluso la considera necesaria para que sea posible asimismo la vida contemplativa. La máxima inicial del capítulo que estamos analizando, en realidad, expresa con bastante precisión el alcance de esta afirmación, al considerar que la vida activa es necesaria, mientras que la vida contemplativa está por cumplimiento o como culminación de la aspiración espiritual de sentirse permanentemente religado a la voluntad divina. Se trata de una relación análoga a la que Llull establece entre la primera intención y la segunda (a las cuales nos hemos referido al comienzo de nuestra exposición), puesto que si aquélla constituye el cumplimiento o realización máxima a que aspira el ser humano, ésta sólo adquiere una razón de ser plena cuando queda subordinada a la consecución de la primera intención.

El capítulo consta de cinco exempla yuxtapuestos. El primero expone cómo un monje que es elegido abad no desea aceptar su nuevo cargo. Los razonamientos por los cuales el monje rechaza el puesto de abad son expuestos por Llull de manera extremadamente ordenada y lógica:

1) El abad está más próximo a la vida activa que el monje claustral.

2) Inversamente, el monje claustral está más próximo a la vida contemplativa.

3) Es preferible mantenerse en la vida contemplativa, más próxima a Dios que la vida activa. 
La decisión del monje de rechazar el cargo de abad implica que, por haberse sentido hasta el momento cercano a Dios, ahora teme que, al pasar a dedicarse a la vida activa, pueda llegar a olvidarle y, por extensión, el conocimiento que hasta ahora tiene de él pueda verse disminuido. Sin embargo, los monjes argumentan que él está moralmente obligado a aceptar el cargo, ya que ése es el deseo de todo el convento. En realidad, se introduce aquí la valoración de que quien es elegido abad se debe a la salud espiritual de los monjes del convento, lo cual supone una gran responsabilidad moral que, si es llevada a cabo con buen criterio, redundará en una ganancia de mérito para el abad (y no hay que olvidar que, para Llull, el mérito será tanto mayor cuanto más elevado sea el rango social detentado y por tanto el número de responsabilidades «civiles» llevadas a una feliz consecución por el sujeto virtuoso). Al final del exemplum se reitera una de las ideas que ya hemos visto anteriormente: la vida activa es un principio necesario para que otros puedan acceder a la vida contemplativa.

Después de haber escuchado el primer exemplum, Fèlix se dispone a responder al ermitaño con otra historia. Este segundo exemplum presenta un caso radicalmente opuesto al primero y persigue un afán claramente moralizador. Ya desde el principio del relato, el mismo Fèlix se maravilla de la conducta insensata de su protagonista: un canónigo que albergaba deseos de convertirse en obispo tras la muerte del que hasta aquel momento ocupaba ese cargo. Para conseguir su objetivo, se preocupó por contentar en todo momento a los canónigos que más adelante lo habrían de elegir como obispo. Se dedicó a llevar una vida aparentemente piadosa, of reciendo sus bienes y sometiéndose a diversas penalidades, pero no por virtud, sino por el mero deseo de ganarse el favor de los demás canónigos. Sin embargo, este esquema argumental mínimo queda rápidamente subordinado a la explicitación directa de la enseñanza que se pretende transmitir en este caso. Fèlix postula sin pestañear que la vida activa, a que está obligado el obispo, implica una fuerte responsabilidad (sin duda a causa de las obligaciones ministeriales y pastorales que conlleva su alto cargo jerárquico), mientras que la vida contemplativa, más apta para los canónigos que para los obispos, permite una mayor libertad. Por ello, se «maravilla» del hecho de que haya tantas personas que prefieran la "servidumbre» de la vida activa, con todos los sinsabores que conlleva, a la «libertad» de la vida contemplativa. Esta inversión de valores que llena a Fèlix de estupor recuerda bastante la inversión denunciada por el personaje de Valor en el capítulo $48 \mathrm{del}$ Blaquerna:

- Creada son valor a significança e a mostrar el valor de mon creador e de mon senyor. Déus fa valer plantes, bèsties, aus, cels, estrelles, quatre elements, metalls, per ço que home haja valor sobre totes estes coses. E cor home no et vol haver, val menys que nulla altra creatura, per ço cor ama desvalor, la qual vol haver, cuidant-se que sia valor (Llull 1998: 123; el subrayado es nuestro).

En un versículo del Llibre d'amic e amat, Llull retoma la dualidad valor/desvalor en términos muy parecidos a los anteriores: 


\section{[283]}

—Digues, amador, què és valor?

Respòs que lo contrari de la valor d'aquest món, la qual és desirada per los falses amadors, vanaglorioses, qui volen valer havents desvalor e per ésser perseguidors de valor (Llull 1995: 165).

En realidad, lo que en este mundo se toma por valor carece de validez desde la perspectiva cristiana de Llull, quien se lamenta recurrentemente en su obra del hecho de que Dios tenga tan pocas personas dispuestas a amarle y a servirle (hasta el extremo de llegar al martirio si fuera necesario). Para Llull, la lógica de la mayoría se sitúa en el extremo opuesto a la entrega incondicional que Dios espera de los seres humanos, para la cual han sido creados. Análogamente, el canónigo del exemplum expuesto por Fèlix, manteniéndose ajeno a la primera intención, antepone la voluntad de sobresalir en la jerarquía de la Iglesia al amor de Dios y al servicio de la comunidad.

El tercer exemplum es narrado por el ermitaño y propone una solución práctica al caso referido en el primer exemplum acerca de la conveniencia de aceptar un cargo eclesiático de importancia. La narración presenta, en primer lugar, a un obispo pecador y de malas costumbres, que a causa de su conducta indecorosa no está nunca tranquilo, lo cual le hace sospechar que en algún momento podría ser envenenado a causa de algún tipo de intriga eclesiástica. Este matiz revela otra de las tesis característicamente lulianas: el pecado constituye en realidad una subversión de la primera intención y una alteración de la correlación de fuerzas habitual en la creación. El ser humano peca cuando actúa contrariamente a la finalidad para la cual ha sido creado haciendo un uso desordenado de sus potencias y prescindiendo de la racional, cuya misión principal es diferenciar entre el bien y el mal. El hombre dispone de los recursos necesarios para evitar el pecado gracias al libre albedrío; sin embargo, cuando su voluntad cede a la tentación, se verifica una alteración del orden correcto de funcionamiento de sus potencias (elementativa, vegetativa, sensitiva, imaginativa y racional) que produce como consecuencia un estado anímico de inquietud moral. Por ello, el hombre pecador no puede sentirse en paz consigo mismo; es lo que le sucede al obispo del exemplum, que a causa de su conducta inadecuada se siente inseguro e incluso teme una agresión procedente del exterior.

Lo más cómico es que esta agresión acaba produciéndose, ya que un arcediano envenena al obispo y lo mata. Como consecuencia, un canónigo es nombrado para ocupar la vacante episcopal; pero éste, a su vez, siente miedo ya que sospecha que también él podría ser envenenado. Sin embargo, un rasgo da cuenta en esta ocasión de las buenas costumbres del nuevo obispo, por oposición a las poco virtuosas de su predecesor: el malestar que siente al verse en la necesidad de abandonar la vida contemplativa por la vida activa, equiparable a la inquietud que identificábamos en el monje del primer exemplum. Precisamente por su conducta virtuosa, el nuevo obispo se decidirá a aceptar el cargo para obtener mayores méritos espirituales y mejorar el regimiento de su predecesor, argumentando que, del mismo modo que las ovejas son encomendadas al pastor, éste se debe a sus ovejas por medio del ejercicio virtuoso de su apostolado. De este 
modo, el exemplum tercero ofrece una alternativa conveniente y deseable a la situación de indefinición en que había quedado el protagonista del exemplum primero. Finalmente, la narración se cierra con la idea de que, gracias a la feliz administración que hará el obispo de la demarcación que tiene asignada, el resto de canónigos podrá entregarse con mayor provecho a la vida contemplativa.

Hasta aquí hemos visto casos en que la vida activa no sólo no se opone a la vida contemplativa, sino que además la permite y favorece. En los dos exempla siguientes veremos que, además, es posible que ambas modalidades se den simultáneamente en una misma persona. Esta perspectiva supone un avance respecto a la de otras obras anteriores del autor, en que uno podría llevarse la impresión de que la vida activa o la vida contemplativa requerían de una fuerte dosis de dedicación exclusiva.

El cuarto exemplum es narrado también por el ermitaño. El protagonista es otro ermitaño que vive retirado en una montaña, enteramente dedicado a la vida contemplativa. Sin embargo, un día piensa en la Pasión de Jesucristo y repara en la escasa atención que muchos hombres le dispensan por no tener en cuenta «la gran amor que Jesucrist lus ha feita». Sintiéndose enojado por tamaña injusticia, decide pasarse a la vida activa, para procurar encaminar a las gentes al amor y conocimiento de Dios.

Detrás de este gesto es posible identificar uno de los grandes conflictos dialécticos permanentes de la filosofía luliana. Por un lado, Llull manifiesta repetidamente su preferencia por la vida contemplativa; sin embargo, cuando el cristiano sincero reflexiona sobre la infidelidad de los creyentes de otras confesiones o de los paganos, no puede evitar irritarse, ya que identifica un claro elemento de distorsión que se opone a la ordenación deseable de la creación y a la primera intención, y como consecuencia se siente motivado a dedicarse a la vida activa para contribuir a la mejora de las condiciones sociales y espirituales de su época. Esto es, en definitiva, lo que lleva al protagonista del Llibre d'Evast e Blaquerna a postergar su voluntad de entregarse completamente a la vida eremítico-contemplativa y a asumir las diferentes dignidades eclesiásticas con que va siendo investido a lo largo de la obra, con la finalidad de reformar la Iglesia desde dentro (haciendo que sea más fiel a los principios evangélicos mediante el ejercicio de la pobreza y de la piedad ascética) e, incluso, de influir en la configuración del poder político o civil. En palabras de Albert Hauf:

En el Blaquerna la constant pugna o contrarietat històrica imperi/papat pel control de la societat medieval és neutralitzada per una harmònica, i no cal dir que del tot utòpica, col-laboració o concordança, ja que ambdós màxims representants del poder col-laboren en la total reforma espiritual instigada pel papa Blaquerna, el qual transforma la corrupta cúria romana, en una espècie de vast recinte conventual, recuperant la virtut o valor i santa vida dels seus membres (Hauf 2002b: 231; los subrayados pertenecen al texto original).

Blaquerna consigue todos sus objetivos de reforma de la sociedad cristiana, cambiando sus formas organizativas (aunque manteniendo una concepción claramente romanocéntrica de la Iglesia) y, sobre todo, sus fundamentos espiritua- 
les, lo cual le convierte en un modelo utópico ejemplar. Esto hace de él, de alguna manera, la manifestación ideal del hombre de acción que postula Llull, el cual sólo debería poder permitirse el retiro a la vida contemplativa tras haber hecho posible la necesaria reordenación de la sociedad cristiana. Nuevamente nos encontramos aquí con que la vía activa se constituye como una necesidad desde una perspectiva social, religiosa e incluso política, frente a la vida contemplativa, que constituye un cumplimiento de índole espiritual.

Después de tomar la decisión de dedicarse a la vida activa, el ermitaño del exemplum que estamos comentando experimenta la razonable tentación de renunciar y volver a su antigua condición, en vista de las penurias que le correspondería sostener en el mundo. Sin embargo, acaba reafirmándose en su empeño al recapacitar sobre las virtudes de la fortaleza, la paciencia y la caridad, y estimulado siempre por el objetivo de hacer que los demás lleguen a amar y a conocer a Dios.

Cierto día, el ermitaño se encuentra con un arzobispo de alto nivel económico, y procura convencerle de que funde un monasterio para religiosos contemplativos. Sin embargo, el arzobispo, que es un mal cristiano ya que en lugar de ceder sus bienes a los pobres más bien se los arrebata, no sólo no accede a las súplicas del ermitaño, sino que ordena que lo castiguen y finalmente lo expulsa de su corte. En este punto nos encontramos con el aspecto más interesante del exemplum: para el ermitaño, «aquell feriment era plaser de fruit de vida activa, del qual naixia, granava e fullava fruit de vida contemplativa». Al ser castigado, el ermitaño lleva la vida activa a su manifestación extrema: la persecución y el sufrimiento por causa de la fe (he aquí nuevamente la concepción del martirio como manifestación suprema del amor a Dios). Las connotaciones místicas de esta última frase del exemplum resultan evidentes, y entroncan con la particular percepción del padecimiento por amor que se puede identificar repetidamente en el Llibre d'amic e amat. La conversión del dolor en placer sólo puede explicarse desde la convicción de que el sufrimiento no es inútil por estar al servicio de la afirmación de una causa justa. Pero, más allá de esta afirmación, que puede llegar a resultar obvia, nos encontramos con que ese sufrimiento placentero entronca directamente con la percepción mística que posibilita la vida contemplativa. Desde un razonamiento basado en el Ars, podríamos decir que cuando el creyente traspasa el umbral de lo comprensible, la voluntad puede dar un último salto más allá y superar todas sus limitaciones previas en la vivencia afectiva de la infinitud divina.

El quinto exemplum, relatado por el ermitaño, presenta en realidad un escaso desarrollo narrativo, pero resulta significativamente decisivo para establecer los ámbitos que corresponden a la vida activa y a la vida contemplativa, ya que su protagonista, un «sant prelat religiós», es capaz de compaginarlas sin contradicción, ya no como consecuencia de una experiencia concreta, como en el caso del exemplum anterior, sino como modo de vivir en sí mismo. Este prelado, al ejercer como tal, se dedica a la vida activa; pero, en tanto que religioso, está asimismo en la vida contemplativa. Por la vida activa se ve forzado a sostener esfuerzos de tipo corporal y espiritual, pero es capaz de soportarlos pacientemente gracias a la aplicación correcta de las tres potencias del alma (cuya fina- 
lidad es recordar, conocer y amar a Dios y menospreciar las vanidades del mundo), que es en realidad el eje fundamental en torno al cual gira la técnica contemplativa propugnada por Llull. A este núcleo narrativo se añade una coda en la cual se pone en relación a este prelado con los apóstoles, ya que éstos, «en quant lo cors, havien vida activa, e en quant la ànima, l'havien contemplativa».

Ha hecho falta llegar hasta este último exemplum para identificar de manera explícita el grado de compenetración posible, en un mismo individuo, entre la vida activa y la vida contemplativa. En cierta medida, y aun a riesgo de equivocarnos, nos atrevemos a afirmar que esta propuesta de convivencia entre ambas formas constituye una superación del esquema bipolar representado por Blaquerna, quien sólo al final de su vida puede dedicarse a la vida contemplativa, que exige de él una dedicación a tiempo completo. Sin embargo, desde la lógica luliana, podríamos considerar que en él esta actitud es justificable ya que previamente ha hecho posible una reforma efectiva (ideal) de la sociedad. En el momento en que se entrega definitivamente a la vida contemplativa, Blaquerna ya había cumplido con la parte «política» de su apostolado.

No se puede perder de vista que Llull es, por encima de todo, un filósofo de la acción y un misionero incansable. Sólo el lector perspicaz puede caer en la cuenta de que en el fondo, para Llull, el fundamento y la razón de ser de la acción hallan precisamente su origen en la vivencia mística: desde la convicción de que el mundo es obra y expresión de Dios, no queda más escapatoria que la de trabajar incansablemente para que toda la creación se ponga a su servicio y aprenda a amarlo, conocerlo y honrarlo. Desde esta perspectiva, resulta fácil comprender en qué medida acción y contemplación están estrechamente relacionadas en el pensamiento luliano. Vienen a ser como las dos caras de una misma moneda. No hay en realidad contradicción alguna cuando, en el Llibre d' $a$ mic e amat, leemos:

\section{[56]}

Puyà-se'n lo cor de l'amich en les altees de l'amat per ço que no fos embargat a amar en l'abís d'aquest món. E con fo a l'amat, contemplà'l ab dolçor e plaer.

E l'amat baxà'l a aquest món per ço que.l contemplàs ab tribulacions e ab languiments (Llull 1995: 83).

\section{BIBLIOGRAFÍA}

ARAGüÉs AlDAZ, José (1996), «Exempla inquirere et invenire. Fundamentos retóricos para un análisis de las formas breves lulianas», en: ALVAR, Carlos / LuCÍA MEGías, José Manuel (eds.), Actas del Congreso Internacional «La literatura en la época de Sancho N", Alcalá de Henares, 21-24 de febrero de 1994, Alcalá de Henares, Universidad de Alcalá, pp. 289-311.

ARAGÜés Aldaz, José (1999), Deus concionator. Mundo predicado y retórica del exemplum en los Siglos de Oro, Amsterdam / Atlanta (Georgia), Rodopi. 
Arbona Piza, Miguel (1976), «Los eximplis en el Llibre de Evast e Blanquerna», Estudios Lulianos 20, pp. 53-70.

BADIA, Lola (1992), «Ramon Llull i la tradició literària», Teoria i pràctica de la literatura en Ramon Llull, Barcelona, Quaderns Crema, pp. 73-95 [artículo original: 1988].

Bohigas, Pere (1981), «Pròleg» a: Llull, Ramon, Llibre de les bèsties, 5. a ed., pp. $5-12$ [1. ${ }^{\text {a }}$ ed.: 1965$]$.

Bonner, Anthony (2002), «The structure of the Arbor scientiae», en: Domínguez REBolras, Fernando / Villalba, Pere / Walter, Peter (eds.), Arbor scientiae, Der Baum des Wissens von Ramon Lull: Akten des Internationalen Kongresses aus Anlaß des 40-jährigen Jubiläums des Raimundus-Lullus-Instituts der Universität Freiburg i. Br., Turnhout, Brepols, pp. 21-34.

Bremond, Claude / LE GofF, Jacques / SCHMITT, Jean-Claude (1982), «L'exemplum», en Typologie des sources du moyen âge occidental 40, Turnhout, Brepols.

BUTINYÀ I JimÉnEZ, Júlia (1996), «El cor del Llibre de meravelles lul-lià», Revista de filología románica 13, pp. 89-103.

CABré, Lluís / Ortín, Marcel / Pujol, Josep (1988), «"Conèixer e haver moralitats bones". L'ús de la literatura en l'Arbre exemplifical de Ramon Llull», Estudios Lulianos 28, pp. 139-167.

Cruz Hernández, Miguel (1977), El pensamiento de Ramon Llull, Madrid, Fundación Juan March / Editorial Castalia.

GAYÀ, Jordi (1980), «Sobre algunes estructures literàries del Libre de Meravelles», Randa 10, pp. 63-69.

Hauf, Albert G. (2002a), «Sobre l'Arbor exemplificalis», en: Domínguez Reboiras, Fernando / Villalba, Pere / Walter, Peter (eds.), Arbor scientiae, Der Baum des Wissens von Ramon Lull: Akten des Internationalen Kongresses aus Anlaß des 40-jährigen Jubiläums des Raimundus-Lullus-Instituts der Universität Freiburg $i$. Br., Turnhout, Brepols, pp. 303-342.

HAUF, Albert G. (2002b), «Les veus del temps. Llull, o l'estètica compromesa», Estudis Baleàrics $72 / 73$, pp. 225-240.

HAUG, Walter / WACHINGER, Burghart (1994), Kleinstformen der Literatur, Tübingen, Max Niemeyer.

JOHNSTON, Mark D. (1994), Ramon Llull's New Rhetoric: Text and Translation of Llull's Rethorica Nova, Davis (California), Hermagoras Press.

Llull, Ramon (1995), Llibre d'amic e amat (edición de Albert SolER), Barcelona, Barcino.

Llull, Ramon (1998), Llibre d'Evast e Blanquerna (edición de Maria Josepa GalloFRÉ), 5. ${ }^{a}$ ed., Barcelona, Edicions 62 / La Caixa [1. ${ }^{a}$ ed.: 1982].

LONGPRÉ, Éphrem (1926), «Lulle, Raymond (le Bienheureux)», Dictionnaire de théologie catholique IX, 1, París, cols. 1072-1141. 
MARTín PASCUAL, Llúcia (2002), “"On pus escura és la semblança, pus altament entén l'enteniment qui aquella semblança entén". Ramon Llull i el didactisme cientificoteològic del Llibre de meravelles», Randa 50 (Homenatge a Miquel Batllori 3), pp. 25-39.

NEORL, Nova Edició de les Obres de Ramon Llull, 7 vols., Palma de Mallorca, Patronat Ramon Llull, 1990-2005.

OE, Obres Essencials de Ramon Llull, 2 vols., Barcelona, Selecta, 1957-1960.

OS, Obres Selectes de Ramon Llull (edición de Anthony BONNER), 2 vols., Palma de Mallorca, Moll, 1989.

PRING-MiLl, Robert D. F. (1991a), «Entorn de la unitat del Llibre d'amic e Amat», Estudis sobre Ramon Llull, Barcelona, Curial / Publicacions de l'Abadia de Montserrat, pp. 279-306 [artículo original: 1962].

PRING-MiLl, Robert D. F. (1991b), «Els recontaments de l'Arbre exemplifical de Ramon Llull: la transmutació de la ciència en literatura», Estudis sobre Ramon Llull, Barcelona, Curial / Publicacions de l'Abadia de Montserrat, pp. 307-317 [artículo original: 1976].

ROL, Raimundi Lulli Opera Latina, Palma de Mallorca, Maioricensis Schola Lullistica (vols. I-v), 1959-1967; Turnhout, Brepols (vols. vI-XXX), 1975-2005.

RUBió I BALAGUER, Jordi (1985a), «La Rhetorica nova de Ramon Llull», Ramon Llull i el lul.lisme, Barcelona, Publicacions de l'Abadia de Montserrat, pp. 202-233 [artículo original: 1946].

RUBIÓ I BALAGUER, Jordi (1985b), «Alguns aspectes de l'obra literària de Ramon Llull», Ramon Llull i el lul.lisme, Barcelona, Publicacions de l'Abadia de Montserrat, pp. 248-299 [artículo original: 1957].

RuвiO, Josep Enric (1997), Les bases del pensament de Ramon Llull. Els origens de l'Art lul-liana, València / Barcelona, Institut Interuniversitari de Filologia Valenciana / Publicacions de l'Abadia de Montserrat.

RUIZ Simon, Josep Maria, «Ramon Llull y las contradicciones aparentes», en: DomíNGUEZ, Fernando / SALAS, Jaime de (eds.), Constantes y fragmentos del pensamiento luliano. Actas del simposio sobre Ramon Llull en Trujillo, 17-20 septiembre 1994, Tübingen, Max Niemeyer, 1996, pp. 19-38.

Trías MerCant, Sebastià (1969), «La ética luliana en el Fèlix de les meravelles», Estudios Lulianos 13, pp. 113-132.

YSERN, Josep-Antoni (1999), «Exempla i estructures exemplars en el primer llibre del $F \grave{e}$ lix», Studia Lulliana 39, pp. 25-54. 